\title{
The Effect of Nigella Sativa Extract on Alpha-ketoglutarate Activity and Histopathologic Changes on Rat Liver Induced by Monosodium Glutamate
}

\author{
Ala Sh Emhemed Eshami ${ }^{1,4^{*}}$, Hidayat Sujuti ${ }^{2}$, Karyono Mintaroem ${ }^{3}$
}

\author{
${ }^{1}$ Student of Master Program, Biomedical Sciences, Department of Pathology, Faculty of Medicine, Brawijaya University, \\ Malang, Indonesia \\ ${ }^{2}$ Department of Biochemistry, Faculty of Medicine, Brawijaya University, Malang, Indonesia \\ ${ }^{3}$ Department of Pathology, Faculty of Medicine, Brawijaya University, Malang, Indonesia \\ ${ }^{4}$ Intensive care and anesthesia department, Faculty of Medical Technology, Tripoli University, Tripoli, Libya
}

\begin{abstract}
Monosodium glutamate (MSG) is a commonly used food additive and found in most soups, fish, and processed meat. The use of MSG in food is growing. However, the fear of consuming MSG has increased in the last few years due to the adverse reactions and toxicity in the liver. Nigella sativa (NS) is used as traditional medicine for the treatment of many diseases. It has been extensively investigated in recent years due to its notable pharmacological properties such as inhibit oxidative stress. The present study was undertaken to investigate the effect of different doses of Nigella Sativa on alpha KGDH activity and liver histology of MSG-induced rats. The animals ( $\mathrm{n}=30$ ) were grouped into A (control), B (treated with MSG 1g/kg.bw ), C (treated with MSG 1g/ $\mathrm{kg} \cdot \mathrm{bw}$ and NS $0.1 \mathrm{~g} / \mathrm{kg} . b w$ ), D (treated with MSG $1 \mathrm{~g} / \mathrm{kg} \cdot \mathrm{bw}_{\text {and }}$ NS $0.2 \mathrm{~g} / \mathrm{kg} \cdot \mathrm{bw}$ ), E (treated with MSG 1g/kg.bw and NS 0.4 $\mathrm{g} / \mathrm{kg} . \mathrm{bw}$ ) and F (given a daily NS extract $0.2 \mathrm{~g} / \mathrm{kg} . \mathrm{bw}$ ). Alpha KGDH activity was investigated using ELISA method and liver histopathology by light microscope. The MSG treatment increased Alpha KGDH activity and disturbed liver architecture, hemorrhage in the central veins, areas of necrosis, vacuolation and increased inflammatory cells infiltration. The condition was normalized by treatment NS on dose 0.2 and $0.4 \mathrm{~g} / \mathrm{kg}$.bw. The findings showed that the administration of MSG increases alpha KGDH and induces damage in liver tissue. Nigella sativa extract can reduce alpha KGDH and prevent liver damage caused by MSG.
\end{abstract}

Keywords: alpha-ketoglutarate dehydrogenases, liver damage, monosodium glutamate, Nigella sativa

\section{INTRODUCTION}

Monosodium glutamate (MSG) is used as flavor enhancer due to its ability to give a sense of savory and deliciousness. MSG has long been utilized by people all over the world as a food flavor enhancer. In Japan and Korea, MSG consumption is more intensive than Europe, which is 1.2 to $1.7 \mathrm{~g} /$ day [1]. MSG caused many pathological effects; it altered the activity and sensitivity of rat hypothalamic-pituitary-adrenocortical axis [2]. It produced neurotoxicity [3], caused obesity and impaired vision [4].

Chronic administration of MSG induced oxidative stress in experimental animals [3,5]. It was documented that MSG produced oxygen-derived free

${ }^{*}$ Corresponding author:

Ala Sh Emhemed Eshami

Student of Master Program, Biomedical Sciences,

Faculty of Medicine, Brawijaya University, Malang, Indonesia

E-mail: Alaeshami@yahoo.com radicals, which induced alterations in decreased antioxidant defenses [5]. Glutamate that is converted into alpha KGDH in the body leads to increase alpha $\mathrm{KGDH}$ activity. The rise in alpha KGDH could produce reactive oxygen species that lead to oxidative stress "imbalances in the equilibrium between pro-oxidants/antioxidants" which results in damaged cells. It was reported that MSG had adversely impacts changes in the liver parenchyma of rats; around the central vein, dilated sinusoids, vacuolation in centrilobular hepatocytes zones, inflammatory cells and nuclei were pyknotic [6]. According to [7], MSG had caused disturbed liver architecture hemorrhage, areas of necrosis and vacuolation in which most nuclei are atrophied.

Herbal medicines have long been viewed as a source of the curative remedy based on religious and cultural traditions [8]. Nigella sativa (NS), referred to as black seed or black cumin, is an annual herbaceous plant that belongs to the family of Ranunculaceae. The 
plant commonly grows in the Middle East, Mediterranean Sea, Eastern Europe and Western and Central Asia. This plant has been extensively investigated in recent years due to its notable pharmacological properties [9]. It has been used widely in Southeast Asian countries, East Central Far Eastern Countries as spice and food preservative as well as a protective and health remedy in traditional folk medicine for the treatment of numerous disorders $[10,11]$. Some research has claimed that NS acts as antioxidant [12]. The present study was carried out to determine whether NS extract prevents the increase of alpha $\mathrm{KGDH}$ activity and the damage in liver tissue in MSG induced rat.

\section{MATERIALS AND METHODS}

\section{Animals and treatments}

Thirty male Wistar rats (2-3 months old) with the average weight about $(200 \pm 20 \mathrm{~g})$ were obtained from physiology laboratory of Brawijaya University, Malang Indonesia. The rats were acclimated to laboratory conditions for one week prior to the experiment. The rats were randomly assigned to six groups. Group A is normal group was given a daily oral dose of Normal saline (1cc) for 30 days. Group B is given a daily oral dose of MSG $1 \mathrm{~g} / \mathrm{kg}$.bw for 30 days. Rats received a daily oral dose of MSG $1 \mathrm{~g} / \mathrm{kg}$.BW with NS extract $0.1 \mathrm{~g} / \mathrm{kg}$. BW, $0.2 \mathrm{~g} / \mathrm{kg}, 0.4 \mathrm{~g} / \mathrm{kg}$.BW for 30 days is group B, C, and D respectively. Group F was given a daily NS extract $0.2 \mathrm{~g} / \mathrm{kg}$. BW for 30 days. Monosodium glutamate (MSG) was obtained from the physiology laboratory, Faculty of Medicine, Brawijaya University. MSG was dissolved in distilled water and given orally by gavage into the rats.

Nigella sativa was obtained from the local market in Malang, Indonesia. The black seeds were crushed by Braun mill mixer, and The extract was prepared as a suspension using distilled water and given orally to groups of male rats in different doses. After 30 days of the experiment, all rats were killed under ether anesthesia. Then, the liver was removed and carefully dissected. The activity of alpha KGDH was measured by using ELISA method and the histopathology of the liver was observed by using a light microscope.

\section{Alfa $K G D H$ activity}

Sample Preparation: Tissue (10 mg) was rapidly homogenized with $100 \mu \mathrm{l}$ cold KGDH Assay Buffer, and kept on ice Centrifuge for 5 minutes. $\alpha-\mathrm{KGDH}$ activity in mitochondria was checked by isolating the mitochondria from fresh tissue or cells using Biovision's Mitochondria Isolation Kit for Tissue and Cultured
Cells (Cat k678-100, BioVision, USA). 5-50 $\mu \mathrm{l}$ sample was added per well. $50 \mu \mathrm{l}$ of KGDH assay buffer was added to the sample. The absorbance was measured immediately at $450 \mathrm{~nm}$ in the kinetic mode for 10-60 $\min$ at $37^{\circ} \mathrm{C}$.

\section{Liver histopathology}

After carefully dissected, the liver tissues were fixed in standard chemical fixative, which was formaldehyde (10\% formalin). Tissue samples were embedded in paraffin. Then, $5 \mathrm{um}$ sections were cut and stained with hematoxylin and eosin [13]. The prepared tissue sections were observed under a research light microscope.

\section{Statistical Analysis}

Data obtained from liver function test were subjected to statistical analysis using one-way analysis of variance (ANOVA) then followed with post hoc test (Least Square Deviation). P value of less than 0.05 was considered significant.

\section{RESULTS AND DISCUSSION \\ Effect of Different Doses of Nigella sativa on alpha $K G D H$ activity of MSG induced Rat}

The Rat groups treated by MSG enzyme alpha$\mathrm{KGDH}$ is showing significantly increased, whereas groups treated by MSG with NS enzyme a-KGDH was still in normal rate, also when NS group is showing aKGDH was still normal compared with MSG group.

Group B (MSG only) shows the greatest effect of MSG on a-KGDH activity and liver histopathology.

Figure 1 shows that Alpha KGDH is significantly increased in group B compared with negative control,

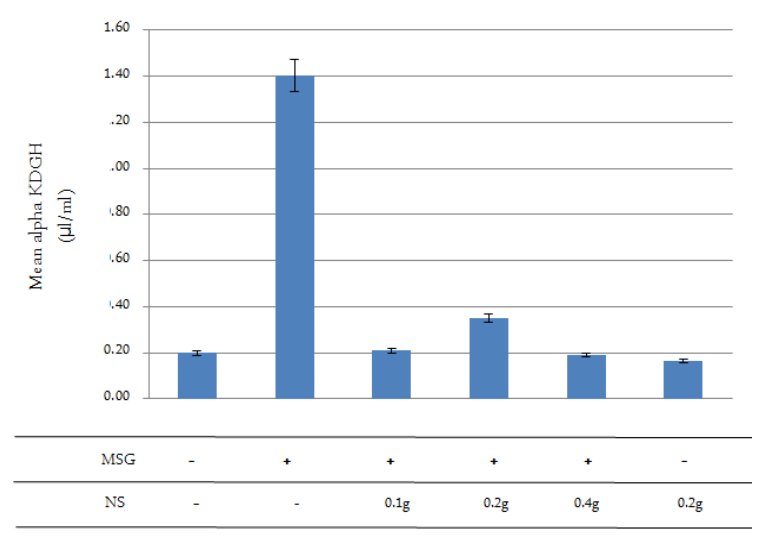

Figure 1. Effect of Different Doses of Nigella sativa on alpha KGDH activity of MSG induced rat. Results are expressed at means $+\mathrm{SD}$. 
$\mathrm{MSG}+\mathrm{NS} 0.1 \mathrm{~g} / \mathrm{kg}, \mathrm{MSG}+\mathrm{NS} 0.02 \mathrm{~g} / \mathrm{kg}, \mathrm{MSG}+\mathrm{NS}$ $0.04 \mathrm{~g} / \mathrm{kg}$, and NS $0.02 \mathrm{~g} / \mathrm{kg}$.

\section{Effect of Different Doses of Nigella sativa extract on Liver Histopathology of MSG Induced Rat}

Group 2A (Control group) shows regular liver architecture, hepatocytes with well demarcated nuclei, intervening sinusoids, normal central vein and features in keeping with normal histology.

The examination of the liver sections of Group 2B (MSG treated group) after the administration of a daily dose of MSG $(1 \mathrm{~g} / \mathrm{Kg})$ for one month shows irregular and distributed architecture, central vein congestion,
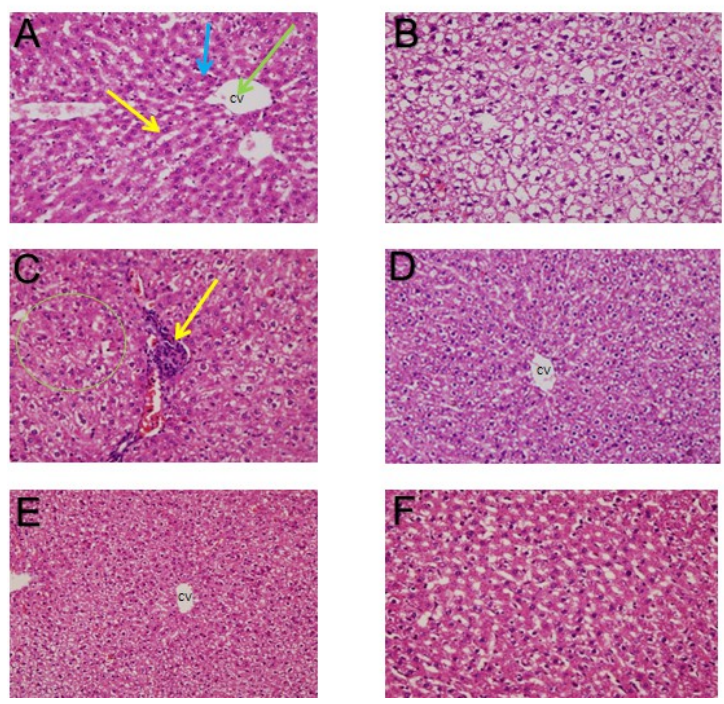

Figure 2. The arrangement of control group liver tissue; sinusoid in yellow arrow, Kupffer cells in blue arrow, and central venous in green arrow (H.E stain,400X) (A). Liver histology in rats treated with MSG $(1 \mathrm{~g} / \mathrm{kg})$ showing areas of necrosis, disappeared sinusoid, and pyknotic cells (H.E stain,400X) (B). Liver histology in rats treated with MSG + NS $(0.1 \mathrm{~g} / \mathrm{kg})$, showing in flammatory cells (yellow arrow) and area of necrosis (green circle) in the liver tissue.( H.E stain,400x) (C). Liver histology in rats treated with MSG + NS $(0.2 \mathrm{~g} / \mathrm{kg})$ showing normal central vein, a somewhat preserved liver architecture, vacuolation of cytoplasm, clear sinusoid, and normal nuclei (H.E stain,200X) (D). Liver histology in rats treated with MSG + NS $(0.4 \mathrm{~g} / \mathrm{kg})$ showing vacuolation of cytoplasm, normal nuclei and central vein.( H.E stain,200X) (E). Liver histology in rats treated with NS $0.02 \mathrm{~g} / \mathrm{kg}$ showing no pathological changes (H.E stain,400X) (F). vacuolation, pyknotic cells, area of necrosis, and many inflammatory cell.

Group 2C Liver sections taken from rats treated with a daily dose of MSG $(1 \mathrm{~g} / \mathrm{kg})$ \& NS $(0.1 \mathrm{~g} / \mathrm{kg})$ for one month shows irregular and distributed architecture, central vein congestion, area of necrosis, and many inflammatory cell.

Group 2D Liver sections taken from rats treated with a daily dose of MSG $(1 \mathrm{~g} / \mathrm{kg})$ \& NS $(0.2 \mathrm{~g} / \mathrm{kg})$ for one month showed somewhat preserved architecture, clear sinusoid and normal nuclei and central vein and vacuolation of cytoplasm.

Group 2E Liver sections taken from rats treated with a daily dose of MSG $(1 \mathrm{~g} / \mathrm{kg})$ \& NS $(0.4 \mathrm{~g} / \mathrm{kg})$ for one month showed more normal liver architecture and normal central vein and nuclie.

Group 2F Liver sections taken from rats treated with a daily dose of NS $(0.2 \mathrm{~g} / \mathrm{kg})$ shows preserved liver architecture, normal central vein, and other accepted normal appearance.

Toxicity of MSG has become the focus of many researchers. The objective of the present study was to determine whether NS extract to prevent increase a$\mathrm{KGDH}$ and necrosis in Liver tissue. The study used 30 male Wistar rats and required 30 days to accomplish.

Group 2B (MSG only) shows the greatest effect of MSG on a-KGDH activity and liver histopathology compared to the other groups. There are significant differences between treatment MSG only and treatment negative control group, MSG + NS $0.1 \mathrm{~g} / \mathrm{kg}$ group, MSG + NS $0.2 \mathrm{~g} / \mathrm{kg}$ group, MSG + NS $0.4 \mathrm{~g} /$ $\mathrm{kg}$ group, and NS $0.2 \mathrm{~g} / \mathrm{kg}$ group. The liver of group 2B show irregular and disturbed liver architecture, area of necrosis, congested central vein and inflammatory cells when observed by microscope. However, $0.1 \mathrm{~g}$ NS group also shows almost similar liver histopathology to that of group 2B; irregular and disturbed liver architecture, area of necrosis, congested central vein and inflammatory cells. In NS 0.2 g groups, few congested central vein was also observed, but there is no necrosis. NS 0.4 g group shows no necrosis, normal congested central vein and few inflammatory cells. It indicates that NS decrease the effect of MSG. In recent studies, the daily administration of MSG significantly increased lipid peroxidation products (MDA and 4-OH alkenals) [14] was the response of the liver and kidney damage which cause change in the liver cells such inflammation and necrosis.

The other groups treated by MSG with NS enzyme a-KGDH was still in normal rate, also when NS group was measured a-KGDH was still normal compared 
with MSG group. The enzyme a-KGDH is also able to generate ROS $[15,16]$. We hypothesized that the increase of a-KGDH in MSG-treated rats may relate to glutamate-stimulated ROS production which induces oxidative stress leading to lipid peroxide.

Significant induction of lipid peroxidation is observed in the thymus of rats treated with MSG. Induction of lipid peroxidation in the liver, kidney, and brain of MSG-treated rats were confirmed by earlier studies [3,17]. This mechanism was confirmed by [17], who found that the monosodium glutamate when administered intraperitoneally at $4 \mathrm{mg} / \mathrm{g}$ of body weight dose, increased the formation of malondialdehyde (MDA) which is oxidative material in the rat's liver and brain. Some evidence argues against the concept that complex I in mitochondria, or in submitochondrial particles, can generate ROS in the absence or even in the presence of its inhibitors [18].

A lesser dose probably just enough to inhibit a$\mathrm{KGDH}$, but not enough to inhibit total production of ROS, whereas increased dose of NS other than inhibit a-KGDH to produce ROS, but also able to inhibit total ROS that produced by other enzymes. The $100 \mathrm{mg} / \mathrm{kg}$ of NS already inhibit a-KGDH and a smaller dose might also be able to inhibit a-KGDH.

It was found that MSG causes damage to liver tissue. It seems that MSG causes irregular and disturbance in liver structure, central vein congestion, inflammation and necrosis. These results were in accordance with that reported by [19] who studied histopathological changes in liver and kidney of rat with monosodium contaminated food. They found that there were foci of necrosis, fatty degeneration and micro vascular changes in the liver. In the kidney, patchy tubular necrosis and interstitial infiltration were present. There are vaculation in cytoplasm, disruption in the membrane cell and nuclei disappearance due to necrosis that happened.

On the other hand, observations on the recent studies indicated significant body weight gain of rats MSG treated group. MSG given could induce an increase in energy intake [19] which could lead to obesity. However, [2,17] attributed the increased body weight to inflammation and edema of liver tissue.

The decrease of a-KGDH is not parallel with the degree on necrosis. a-KGDH is decreasing very much with the first dose of NS treatment, but necrosis is not similar with the activity of a-KGDH. It could mean the other molecular mechanism may play an important role the regulation in necrosis, and inflammatory cell infiltration.

\section{CONCLUSIONS}

This present study shows that administration of MSG increases alpha KGDH activity and induces damage in liver tissue. Nigella sativa extract can reduce alpha $\mathrm{KGDH}$ activity and prevent liver damage caused by MSG.

\section{ACKNOWLEDGMENT}

The authors acknowledge all technical assistant in Pathology Anatomy Laboratory and Physiology Laboratory.

\section{REFERENCES}

1. Beyreuther, Biesalski HK, Fernstrom JD, Grimm P, Hammes WP, Heinemann U, Kempski O, Stehle P, Steinhart H, Walker R (2006) Consensus meeting: monosodium glutamate an update. European Journal of Clinical Nutrition, Nature Publishing Group. 1-10.

2. Park CH, Choi SH, Piao Y, Kim S, Lee YJ, Kim HS, Jeong SJ, Rah JC, Seo JH, Lee JH, Jung YJ, Suh YH (2000) Glutamate and aspartate impair memory retention and damage hypothalamic neurons in adult mice. Toxicol Lett. 115(2): 117-25.

3. Singh P, Mann AK, Mangat HK et al. (2003) Prolonged glutamate excitotoxicity: Effects on mitochondrial antioxidants and antioxidant enzymes. Mol Cell Biochem. 243: 139-145.

4. Praputpittaya C, Wililak A (2003) Visual performance in monosodium Lglutamate-treated rats. Nutr. Neurosci. 6: 1181-1187.

5. Diniz YS, Fernandes-Aah, Campos-Ke, Mani-F (2004) Toxicity of hypercaloric diet and monosodium glutamate: Oxidative stress and metabolic shifting in hepatic tissue. Food-and- chemical - Toxicology. 42: 2(313-319).

6. Bhattacharya T, Bhakt A and Ghosh H.M (2011) Long term effect of monosodium glutamate221in liver of albino mice after neo-natal exposure. Nepal Med Coll J. 13(1): 11-16.

7. Hanaa FW, Saleh E (2006) The Effect of Monosodium Glutamate (MSG) On Rat Liver And The Ameliorating Effect Of Guanidino Ethane Sulfonic acid (GES) (Histological, Histochemical and Electron Microscopy Studies). The Egyptian Journal of Hospital Medicine. 24: 524-538.

8. Ghosheh OA, Houdi AA, Crooks PA (1999) High performance liquid chromatographic analysis of the pharmacologically active quinones and related compounds in the oil of the black seed (Nigella sativa L.). J Pharm Biomed Anal. 19: 757-762.

9. Dubick MA (1986) Historical Perspectives On The Use Of Herbal Preparations To Promote Health. Journal Of Nutrition. 116: 1348-1354. 
10. Chopra RN, Nayar SL, Chopra IC (1956) Glossary of Indian medicinal plants. New Delhi. CSIR. p. 175.

11. Nadkarni K (1976) Crocus sativus, Nigella sativa, In: Nadkarni KM (editor), Indian material medica. Popular Prakashan. Bombay. pp. 386-411.

12. Mansour MA, Nagi MN, El-Khatib AS, Al-Bekairi AM (2002) Effects of thymoquinone on antioxidant enzyme activities, lipid peroxidation and DT-diaphorase in different tissues of mice: a possible mechanism of action. Cell Biochem Funct. 20: 143-51.

13. Drury RAB, Wallington EA (1976) Carleton's Histological Technique. Oxford University Press. New York. 4th ed. P. 129.

14. Liebshutz. J..Airoldi. L.. Brownstein. M.J.. Chinn. N.G. and Wurtman. R.J.. Regional distribution of endogenous and par. enteral glutamate. aspartate and glutamine in rat brain. Biochem. Pharmacal. 26 (1977) 443-446.

15. Starkov AA, Fiskum G, Chinopoulos C, Lorenzo BJ, Browne SE, et al. (2004) Mitochondrial alphaketoglutarate dehydrogenase complex generates reactive oxygen species. J Neurosci. 24: 7779-7788.

16. Bunik VI, Fernie AR (2009) Metabolic control exerted by the 2-oxoglutarate dehydrogenase reaction: a cross-kingdom comparison of the crossroad between energy production and nitrogen assimilation. Biochem J. 422: 405-421.

17. Farmobi, E.O. and Onyema, O.O. 2006. Monosodium glutamate-induced oxidative damage and genotoxicity in the rat: Modulatory role of vitamin $\mathrm{C}$, vitamin $\mathrm{E}$ and quercetin. Hum.Exp.Toxicol. 25: 251-259.

18. Bopanna K, Balaraman R and Nadig R S (1999) Organotropicultrastructural changes produced by monosodium glutamate in rats on atherogenic diet: effect of S-allyl cysteine sulphoxide. Indian J. of Pharmacology. 31(4): 26674 .

19. Bergen HT, Mizuno TM, Taylor J (1998) Hyperphagia and weight gain after gold-thioglucose and monosodium glutamate: relation to hypothalamic neuropeptide. Y. Endocrin. 139: 4483-4488. 